\title{
Marcadores Morfofisiológicos e Isoenzimáticos na Análise da Diversidade Genética de Isolados de Acremonium strictum*
}

\author{
Hudson Teixeira1, Maria das Graças G. C. Vieira ${ }^{2}$ \& José C. Machado³ \\ 'Departamento de Fitopatologia, Universidade Federal de Viçosa, CEP 36570-000, Viçosa, MG, tel: (31) 3899-1096, \\ e-mail: hudsont@ufv.br; ${ }^{2}$ Departamento de Agricultura, e-mail: sementes@ ufla.br; Departamento de Fitopatologia, \\ Universidade Federal de Lavras, Cx. Postal 37, CEP 37200-000, Lavras, MG, tel: (35) 3829-1470, e-mail: machado@ufla.br
}

(Aceito para publicação em 11/05/2004)

Autor para correspondência: Hudson Teixeira

TEIXEIRA, H., VIEIRA, M.G.G.C. \& MACHADO, J.C. Marcadores morfofisiológicos e isoenzimáticos na análise da diversidade genética de isolados de Acremonium strictum. Fitopatologia Brasileira 29:413-418. 2004.

\section{RESUMO}

Os fungos Acremonium strictum e Fusarium verticillioides normalmente apresentam algumas similaridades morfológicas. Este fator dificulta sua diferenciação em sementes, particularmente quando ocorrem simultaneamente. A análise de isoenzimas tem possibilitado o desenvolvimento de métodos rápidos, sensíveis e específicos no diagnóstico de fitopatógenos em complemento à análise morfológica. Este trabalho objetivou caracterizar e dimensionar a diversidade genética de dez isolados de A. strictum obtidos de sementes de milho (Zea mays), provenientes de diferentes regiões produtoras brasileiras por meio da análise de nove marcadores morfofisiológicos e de cinco sistemas isoenzimáticos (aldolase, esterase, fosfatase ácida, fosfatase alcalina e malato desidrogenase). Objetivou-se ainda diferenciar os isolados de A. strictum de F. verticillioides por meio das técnicas citadas. A eletroforese de isoenzimas forneceu um total de 28 bandas polimórficas. Aspectos como pigmentação da colônia, velocidade e taxa de crescimento, produção de massa e densidade miceliais, e a análise isoenzimática tornaram possível e seguro o agrupamento de isolados de A. strictum e sua diferenciação de $F$. verticillioides. Os isolados de A. strictum apresentaram variabilidade intraespecífica entre $0 \%$ e $89,5 \%$. Para a maioria dos casos não foi possível correlacionar a similaridade fenotípica com a origem geográfica dos isolados de A. strictum.

Palavras-chave adicionais: eletroforese, isoenzimas, variabilidade, fungos fitopatogênicos, sementes.

\section{ABSTRACT}

Morphophysiological and isoenzymatic markers in a genetic diversity analysis of Acremonium strictum isolates

Differentiation between Acremonium strictum and Fusarium verticillioides in corn (Zea mays) seeds is very difficult because they present morphological similarities. Isoenzimatic analysis has been applied with success, allowing the development of fast, sensible and specific methods for diagnosis of plant pathogens in complement to morphological analysis. The objectives of this work were to characterize and evaluate the genetic diversity of ten isolates of $A$. strictum associated with corn seeds from different Brazilian regions by means of morphophysiological and isoenzymes analysis, in comparison to one isolate of $F$. verticillioides. Nine morphophysiological characteristics and five isoenzymes systems (aldolase, esterase, acid phosphatase, alcalin phosphatase and malate dehydrogenase) were considered in this study. Isoenzymatic analysis produced 28 polymorphic bands. Colony pigmentation, growth rates, weight, mycelial density and isoenzymatic analysis were efficient for grouping A. strictum isolates and to distinguish them from $F$. verticillioides. The isolates of $A$. strictum showed variable intraspecific diversity between $0 \%$ to $89,5 \%$. No phenotypic similarities were correlated with geographic origin of the A. strictum isolates.

\section{INTRODUÇÃO}

Técnicas moleculares baseadas na análise de isoenzimas têm sido aplicadas com êxito em diversas áreas da Micologia, possibilitando o desenvolvimento de métodos rápidos, sensíveis e específicos no diagnóstico de fitopatógenos. A caracterização morfológica, embora útil, é bastante limitada devido ao baixo número de caracteres passíveis de serem analisados (Fungaro, 2000). Marcadores morfológicos, como pigmentação, textura, forma marginal e velocidade de crescimento da colônia, produção de estruturas típicas, presença ou ausência de zonas concêntricas (Burgess et al., 1995; Urben \& Oliveira, 1999), são, de modo geral, altamente instáveis e dependentes da composição do meio utilizado, condições de incubação e da própria variação do patógeno. Portanto, são subjetivos, pouco conclusivos e podem induzir a erros de interpretação quanto à identificação das espécies em estudo, já que muitas vezes, colônias atípicas de um dos organismos podem assemelhar-se às colônias do outro.

A irrestrita adoção de marcadores isoenzimáticos no diagnóstico e determinação da diversidade genética de fitopatógenos deve-se, principalmente, à sua simplicidade de uso, rapidez, segurança e amplitude dos resultados obtidos. Vieira (1996) distinguiu satisfatoriamente, isolados de Colletotrichum gossypii South e de Colletotrichum gossypii (South) var. cephalosporioides A. S. Costa obtidos de sementes de algodoeiro (Gossypium hirsutum L.) por meio 
H. Teixeira et al.

desta técnica. Podem ser citados também experimentos que objetivaram dimensionar a variabilidade genética de isolados de Fusarium oxysporum f. sp. lycopersici Snyder \& Hansen (Andrade et al., 1997), Fusarium moniliforme Sheldon (Camargo, Menezes \& Assis, 1997), Botryodiplodia theobromae Pat. (Lima et al., 1997), Myrothecium roridum Tode ex. Fr. (Machado et al., 1997) e Colletotrichum guaranicola Albuquerque (Véras et al., 1997).

A diagnose precisa de patógenos morfologicamente semelhantes, como Acremonium strictum W. Gams e Fusarium verticillioides (Sacc.) Nirenberg, em lotes de sementes de milho (Zea mays L.) é uma necessidade e representa uma proteção indispensável para o sistema de produção de sementes. Dessa forma, os objetivos deste trabalho foram caracterizar e dimensionar a diversidade genética de isolados de A. strictum por meio da análise de marcadores morfofisiológicos e isoenzimáticos, correlacionar tais aspectos com a origem geográfica dos isolados e diferenciá-los de um isolado de $F$. verticillioides por meio das técnicas citadas.

\section{MATERIAL E MÉTODOS}

\section{Obtenção e multiplicação dos isolados fúngicos}

Foram utilizados dez isolados de A. strictum e um de F. verticillioides obtidos de sementes de milho pelo método de incubação em papel de filtro (Limonard, 1966). Os isolados de $A$. strictum foram provenientes de duas diferentes localidades representativas de cinco importantes estados produtores brasileiros (Tabela 1). A multiplicação de $A$. strictum e F. verticillioides constou no cultivo em meio MA (Smith e Onions, 1994) a $20^{\circ} \mathrm{C}$, fotoperíodo de $12 \mathrm{~h}$ de luz, por dez dias em BOD.

\section{Marcadores morfofisiológicos na análise da diversidade de A. strictum}

Os isolados de A. strictum e F. verticillioides obtidos foram cultivados em meio MA, recoberto por quadrado de papel celofane, de dimensão padronizada $\left(56 \mathrm{~cm}^{2}\right)$, previa-

TABELA 1 - Origem geográfica dos isolados de Acremonium strictum (AS1 a AS10) e de Fusarium verticillioides (FV11) obtidos de sementes de milho (Zea mays) e utilizados nos ensaios

\begin{tabular}{lllcl}
\hline \hline \multirow{2}{*}{ Isolado } & Origem da amostra & Localização & $\begin{array}{c}\text { Altitude } \\
(\mathbf{m})\end{array}$ & Hospedeiro \\
\hline AS1 & Sete Lagoas - MG & Centro & 761 & 8447 \\
AS2 & Uberlândia - MG & Triângulo & 863 & C - 909 \\
AS3 & Miguelópolis - SP & Norte & 510 & AG - 3010 \\
AS4 & Itaí - SP & Sudoeste & 614 & C - 909 \\
AS5 & S $^{\text {to }}$ Antônio Platina - PR & Norte & 505 & C - 444 \\
AS6 & S $^{\text {ta }}$ Terezinha Itaipu - PR & Sudoeste & 218 & AG - 9010 \\
AS7 & Vicentinópolis - GO & Sul & 646 & C - 901 \\
AS8 & Itumbiara - GO & Sul & 448 & AG - 1051 \\
AS9 & Passo Fundo - RS & Norte & 687 & ----- \\
AS10 & Cruz Alta - RS & COeste & 452 & AG - 3010 \\
FV11 & Sete Lagoas - MG & Centro & 761 & ------- \\
\hline
\end{tabular}

mente tratado com EDTA $0,1 \mathrm{mM}$ e esterilizado a $120^{\circ} \mathrm{C}$ por 30 min. Após dez dias de incubação foram avaliadas as variáveis morfofisiológicas (Tabela 2).

Na determinação da velocidade e taxa de crescimento micelial foi medido o raio médio da colônia (Gams, 1971). Com relação às variáveis produção de massa micelial e densidade micelial, o peso em miligramas refere-se às estruturas fúngicas desenvolvidas sobre o papel celofane. Partindo dos dados morfofisiológicos de A. strictum e $F$. verticillioides coletados, construiu-se uma matriz de dissimilaridade, a qual originou um dendrograma (UPGMA, NTSYS-pc, versão 2.02, coeficiente Simple Matching). O delineamento estatístico adotado foi o inteiramente casualizado, com onze isolados fúngicos, cinco repetições e parcela constituída por uma placa de Petri de $9 \mathrm{~cm}$ de diâmetro contendo uma colônia de $A$. strictum ou de $F$. verticillioides em desenvolvimento.

\section{Marcadores isoenzimáticos na análise da diversidade de A. strictum}

Cinco discos de meio MA com $5 \mathrm{~mm}$ de diâmetro, contendo micélio de $A$. strictum e $F$. verticillioides foram retirados da periferia de colônias com dez dias de idade e transferidos para frascos Erlenmeyer contendo $50 \mathrm{ml}$ de meio líquido, composto de: $\mathrm{NaNO}_{3}-2 \mathrm{~g} / \mathrm{l} ; \mathrm{KH}_{2} \mathrm{PO}_{4}-1 \mathrm{~g} / \mathrm{l} ; \mathrm{MgSO}_{4}$. $7 \mathrm{H}_{2} \mathrm{O}-0,5 \mathrm{~g} / \mathrm{l}$; sacarose $-15 \mathrm{~g} / \mathrm{l}$; água destilada e esterilizada - $1.000 \mathrm{ml} ; 10 \mathrm{ml}$ de solução mineral (elementos traços): $\mathrm{FeSO}_{4} \cdot 7 \mathrm{H}_{2} \mathrm{O}-20 \mathrm{mg} / \mathrm{l} ; \mathrm{ZnSO}_{4} \cdot 7 \mathrm{H}_{2} \mathrm{O}-100 \mathrm{mg} / \mathrm{l} ; \mathrm{Na}_{2} \mathrm{MoO}_{4}$ . $7 \mathrm{H}_{2} \mathrm{O}-2 \mathrm{mg} / \mathrm{l} ; \mathrm{CuSO}_{4} \cdot 5 \mathrm{H}_{2} \mathrm{O}-2 \mathrm{mg} / \mathrm{l} ; \mathrm{MnCl}_{2} \cdot 4 \mathrm{H}_{2} \mathrm{O}-2$ $\mathrm{mg} / \mathrm{l} ; \mathrm{pH}$ do meio $=6,5$. Os fungos foram mantidos a $20^{\circ} \mathrm{C}$, sem agitação, no escuro, por sete dias, sendo o micélio obtido coletado a vácuo e macerado em nitrogênio líquido em presença de areia de quartzo esterilizada e antioxidante PVP. Com relação à extração e análise eletroforética de isoenzimas, para cada isolado foram utilizados $150 \mathrm{mg}$ de micélio fresco e macerado, os quais foram colocados em microtubos de $2 \mathrm{ml}$, adicionando-se, em seguida, $300 \mu \mathrm{lde}$ tampão de extração (Tris-HCl 0,2 M, pH 8,0; 0,8\% PVP; 4\% PEG 6000; 0,1\% BSA; 0,1\% $\beta$-mercaptoetanol). A mistura foi homogeneizada e centrifugada a $16.000 \mathrm{xg}$ por $25 \mathrm{~min}$, a $4^{\circ} \mathrm{C}$. Do extrato de cada amostra foram aplicados $100 \mu \mathrm{l}$ em géis de poliacrilamida confeccionados em sistema descontínuo (4,5\% e 7,5\%). As isoenzimas foram separadas em campo elétrico por aproximadamente $4 \mathrm{~h}$, a $4^{\circ} \mathrm{C}$. O sistema tampão gel/eletrodo utilizado foi Tris-glicina $\mathrm{pH} 8,9$. Após migração, os géis foram revelados para os sistemas enzimáticos aldolase (ALD), esterase (EST), fosfatase ácida (ACP), fosfatase alcalina (ALP), malato desidrogenase $(\mathrm{MDH})$, peroxidase (PO) e superóxido dismutase (SOD), segundo metodologia descrita por Alfenas (1998). Os géis foram avaliados quanto à presença (valor 1) ou ausência (valor 0) de bandas polimórficas entre os genótipos de $A$. strictum e $F$. verticillioides. Determinou-se a estimativa de dissimilaridade genética por meio da construção de um dendrograma (UPGMA, NTSYS-pc, versão 2.02, coeficiente de Jaccard). 
Marcadores morfofisiológicos e isoenzimáticos na análise da diversidade genética...

\section{RESULTADOS E DISCUSSÃO}

\section{Marcadores morfofisiológicos na análise da diversidade de A. strictum}

Com base na classificação de aspectos morfofisiológicos adotada neste trabalho (Tabela 2) e de acordo com os resultados mostrados na Tabela 3, observou-se que os isolados de A. strictum apresentaram elevada variação fenotípica quanto ao crescimento micelial típico (C.M.T.), textura do micélio (T.M.), formação in vitro de feixes de hifas (F.F.H.), forma marginal da colônia (F.M.C.) e pigmentação da colônia (P.a.C.; P.v.C.). Foram observados também resultados coincidentes entre alguns isolados de $A$. strictum e o isolado de $F$. verticillioides com relação ao crescimento micelial típico, textura do micélio, formação de feixes de hifas e forma marginal da colônia. Reforçando os relatos de Gams (1971), os isolados de A. strictum se desenvolveram mais lentamente em meio MA e, conseqüentemente, produziram menos massa micelial in vitro quando comparados a $F$. verticillioides. Os isolados de $A$. strictum apresentaram uma ampla faixa de cores, variando do bege (B) ao rosa alaranjado (Ra), em múltiplas combinações, predominando a pigmentação rosa e suas variantes. Por outro lado, F. verticillioides sempre apresentou no verso e anverso das colônias pigmentação violeta (Vio) intensa e suficientemente diferenciadora dos demais isolados (Tabela 3). Segundo Gams (1971), a espécie A. strictum produz micélio que pode variar do branco ao rosa, o que confirmou em parte os resultados obtidos neste trabalho. De acordo com Gois et al. (1997), Valim-Labres et al. (1997) e Cerqueira et al. (1999), algumas características morfológicas são subjetivas, logo, dependentes da interpretação de quem as avalia.

Com base nos aspectos morfofisiológicos avaliados,

TABELA 2 - Variáveis morfofisiológicas consideradas na análise de isolados de Acremonium strictum de Fusarium verticillioides obtidos de sementes de milho (Zea mays) e cultivados em meio malte-ágar (MA)

\begin{tabular}{|c|c|c|c|c|c|}
\hline \multicolumn{6}{|l|}{ Variável morfofisiológica } \\
\hline Crescimento micelial típico & Superficial (S) & Aéreo (A) & & & \\
\hline Textura do micélio & Lisa $(\mathrm{L})$ & Floculosa (F) & Cotonosa $(\mathrm{C})$ & & \\
\hline Formação in vitro de feixes de hifas & Ausente (-) & Presente $(+)$ & & & \\
\hline Forma marginal da colônia & Regular $(\mathrm{R})$ & Irregular (I) & & & \\
\hline Pigmentação do anverso e verso da & Bege (B) & Rosa claro $(\mathrm{Rc})$ & Rosa salmão (Rs) & Rosa alaranjado $(\mathrm{Ra})$ & Violeta (Vio) \\
\hline colônia (Munsell, 1976) & $2,5 \mathrm{Y}-8,5 / 2$ & $2,5 \mathrm{R}-9 / 2$ & $10 \mathrm{R}-7 / 10$ & $10 \mathrm{R}-6 / 14$ & $2,5 \mathrm{R}-5 / 8$ \\
\hline $\begin{array}{l}\text { Velocidade de crescimento micelial } \\
(\mathrm{mm} / 10 \text { dias })(\mathrm{Gams}, 1971)\end{array}$ & $<10 \mathrm{~mm}$ & $10<x<30 \mathrm{~mm}$ & $>30 \mathrm{~mm}$ & & \\
\hline $\begin{array}{l}\text { Taxa de crescimento micelial } \\
\left(\mathrm{mm} / 2 \mathrm{em} \text { dois dias, até o } 10^{\circ} \mathrm{dia}\right) \\
(\mathrm{Gams}, 1971)\end{array}$ & $<3 \mathrm{~mm}$ & $3<\mathrm{x}<6 \mathrm{~mm}$ & $>6 \mathrm{~mm}$ & & \\
\hline $\begin{array}{l}\text { Producao de massa micelial } \\
\text { (mg/10 dias) }\end{array}$ & $<10 \mathrm{mg}$ & $10<x<30 \mathrm{mg}$ & $>30 \mathrm{mg}$ & & \\
\hline $\begin{array}{l}\text { Densidade micelial } \\
\left(\mathrm{mg} / 56,25 \mathrm{~cm}^{2}\right)\end{array}$ & $<3 \mathrm{mg}$ & $3<x<6 \mathrm{mg}$ & $>6 \mathrm{mg}$ & & \\
\hline
\end{tabular}

TABELA 3 - Avaliação de variáveis morfofisiológicas de isolados de Acremonium strictum (AS1 a AS10) de Fusarium verticillioides (FV11) obtidos de sementes de milho (Zea mays) e cultivados em meio malteágar (MA)

\begin{tabular}{lcccccccccc}
\hline \hline \multirow{2}{*}{ Isolado } & \multicolumn{10}{c}{ Variáveis morfofisiológicas } \\
\cline { 2 - 11 } & C.M.T.* & T.M. & F.F.H. & F.M.C. & P.a.C. & P.v.C. & V.C. & T.C. & P.M. & D.M. \\
\hline AS1 & S & L-F & - & R & Rs-Ra & Rs-Ra & 19,0 & 3,3 & 13,0 & 3,5 \\
AS2 & S-A & F-C & + & I & Rs-Ra & Rs-Ra & 20,0 & 3,3 & 12,8 & 3,5 \\
AS3 & S-A & L-C & + & R & Rc-Ra & Rc-Ra & 23,0 & 3,9 & 15,3 & 3,7 \\
AS4 & S-A & F-C & + & R & B-Rs & B-Rs & 22,0 & 3,8 & 15,0 & 3,7 \\
AS5 & S-A & F-C & + & R & B-Ra & B-Ra & 24,0 & 4,3 & 17,6 & 4,0 \\
AS6 & S & L-F & - & R & Rs-Ra & Rs-Ra & 23,0 & 4,2 & 15,7 & 4,0 \\
AS7 & S-A & F-C & + & I & Rs-Ra & Rs-Ra & 18,0 & 3,3 & 13,2 & 3,3 \\
AS8 & S-A & L-C & + & I & B-Rs & B-Rs & 20,0 & 3,4 & 12,0 & 3,0 \\
AS9 & S & L-F & - & R & B-Ra & B-Ra & 22,0 & 3,6 & 15,0 & 3,3 \\
AS10 & S & L-F & - & R & Rs-Ra & Rs-Ra & 23,0 & 4,3 & 15,8 & 4,0 \\
FV11 & S-A & L-C & - & R & Vio & Vio & 35,0 & 7,2 & 33,0 & 6,8 \\
\hline
\end{tabular}

*C.M.T. (crescimento micelial típico); T.M. (textura do micélio); F.F.H. (formação in vitro de feixes de hifas); F.M.C. (forma marginal da colônia); P.a.C. (pigmentação do anverso da colônia); P.v.C. (pigmentação do verso da colônia); V.C. (velocidade de crescimento micelial); T.C. (taxa de crescimento micelial); P.M. (produção de massa); D.M. (densidade micelial). 
a pigmentação da colônia, a velocidade e taxa de crescimento, a produção de massa e a densidade micelial tornaram possível e seguro o agrupamento de isolados de A. strictum e sua diferenciação de $F$. verticillioides em meio MA. Os isolados de A. strictum apresentaram coeficiente de dissimilaridade intraespecífica variando de 0 a $60 \%$ e média de $37 \%$, enquanto que a dissimilaridade interespecífica observada variou de $70 \%$ (AS3 e FV11) a 90\% (AS2 e FV11; AS7 e FV11). A similaridade entre os isolados de $A$. strictum, pouco acima de $60 \%$, sugere que a existência de um grande número de subpopulações do patógeno é pouco provável. Em alguns casos, pares de isolados provenientes de um mesmo estado brasileiro apresentaram ora menor, ora maior coeficiente de dissimilaridade do que aqueles provenientes de estados diferentes. A explicação provável para estes resultados talvez resida no fato de que os isolados de A. strictum, embora oriundos de um mesmo estado, foram obtidos de amostras de sementes de milho produzidas em localidades com características edafoclimáticas distintas. Desse modo, podese afirmar que o agrupamento de isolados de A. strictum, baseado somente em características morfofisiológicas, não foi suficiente para estabelecer qualquer correlação entre similaridade fenotípica e a origem geográfica dos mesmos. Este fato reforça o relato de Valim-Labres et al. (1997), no qual os autores sugerem que a diversidade morfológica não é ocasionada unicamente por pressões do ambiente, decorrentes de diferenças geográficas como temperatura e umidade relativa do ar e o fotoperíodo. Neste trabalho observou-se que a variabilidade morfofisiológica pode também estar sendo influenciada por algum fator intrínseco ao patógeno, genótipo do hospedeiro, ou ainda, à interação entre estes. De acordo com marcadores morfofisiológicos, os isolados fúngicos foram distribuídos em três grupos, considerando um limite arbitrário de 30\% de distância genética relativa (Figura 2A). O grupo 1 foi formado pelos isolados AS1, AS6, AS10, AS9; grupo 2: AS2, AS7, AS3, AS4, AS5, AS8; e o grupo 3: FV11.

\section{Marcadores isoenzimáticos na análise da diversidade de A. strictum}

Os perfis eletroforéticos da liase ALD, das hidrolases EST, ACP e ALP, bem como da oxirredutase MDH exibiram um total de 28 bandas polimórficas, tendo sido considerada elevada a atividade em todos os sistemas enzimáticos citados (Figura 1). Alguns autores têm relatado atividade enzimática em outras espécies fúngicas para os sistemas avaliados neste ensaio. Como exemplo, são citados os experimentos de Leuchtmann \& Clay (1990) utilizando a enzima ALD na detecção de variabilidade entre isolados de Acremonium sp., bem como a utilização dos sistemas ACP e MDH na determinação da diversidade genética de strains de Gibberella fujikuroi (Sawada) Wollenw. e Fusarium oxysporum (Schlecht.) Snyder \& Hansen (Huss et al., 1996) e, ainda, os trabalhos de Kerssies et al. (1994) e Skovgaard \& Rosendahl (1998) na identificação de Fusarium sp. e F. oxysporum utilizando o sistema EST. No presente trabalho, a distância genética relativa mínima e máxima entre os isolados de $A$.

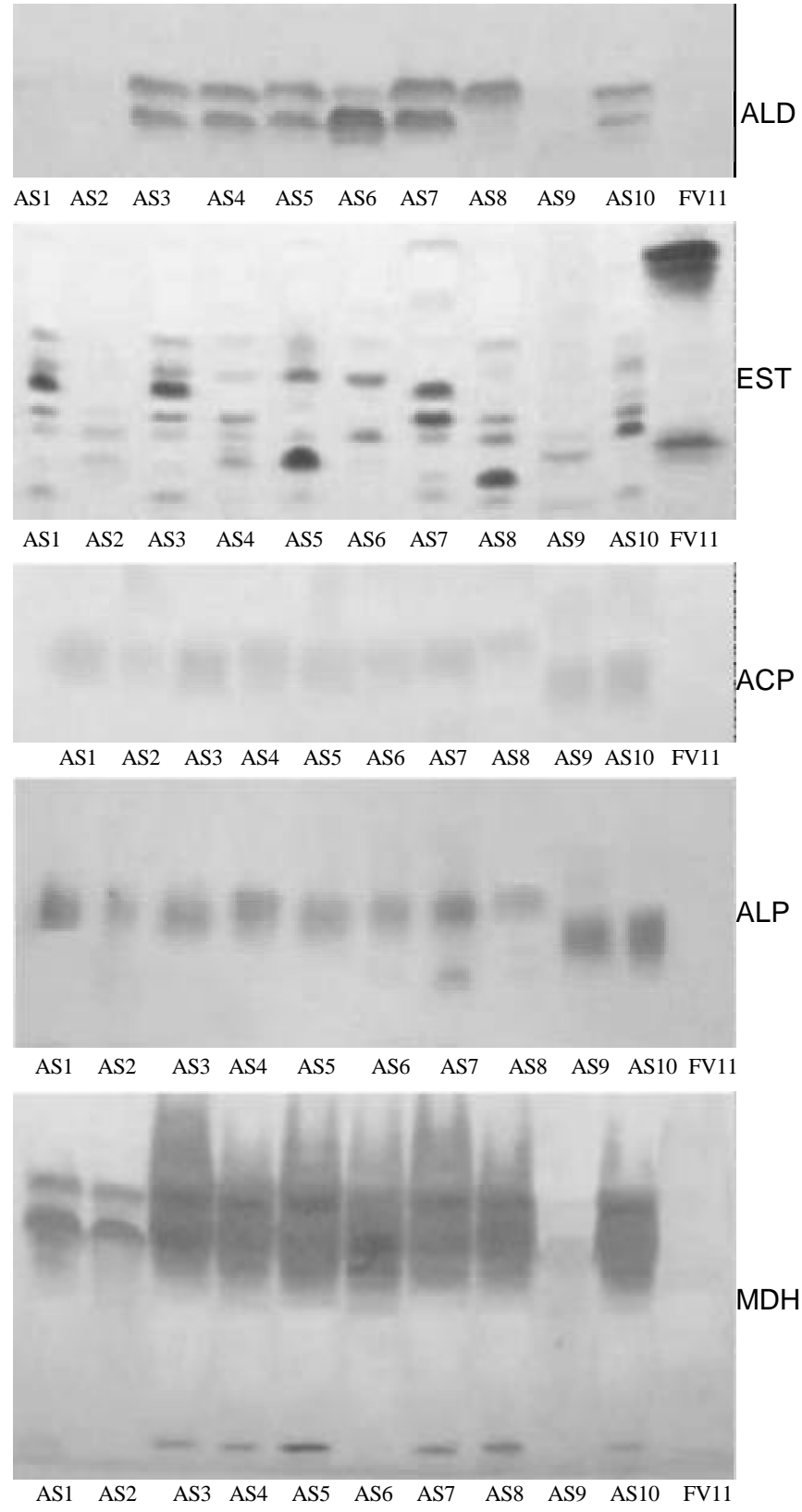

FIG. 1 - Padrões isoenzimáticos para isolados de Acremonium strictum (AS1 a AS10) e de Fusarium verticillioides (FV11) revelados para as isoenzimas aldolase (ALD), esterase (EST), fosfatase ácida (ACP), fosfatase alcalina (ALP) e malato desidrogenase (MDH).

strictum foram observadas entre os pares AS1 e AS3 (25\%) e AS7 e AS9 (89,5\%), respectivamente. A distância média intraespecífica em $A$. strictum foi de 58,5\%. Estes resultados estão de acordo com aqueles obtidos na análise morfofisiológica dos isolados, no que diz respeito à baixa variabilidade detectada entre isolados de A. strictum. A dissimilaridade entre $A$. strictum e $F$. verticillioides variou de $87,5 \%$ (AS7 e FV11) a 100\% (AS9 e FV11).

A variabilidade dos perfis isoenzimáticos entre os isolados fúngicos foi resumida na Figura 2B. Os isolados 
Marcadores morfofisiológicos e isoenzimáticos na análise da diversidade genética...

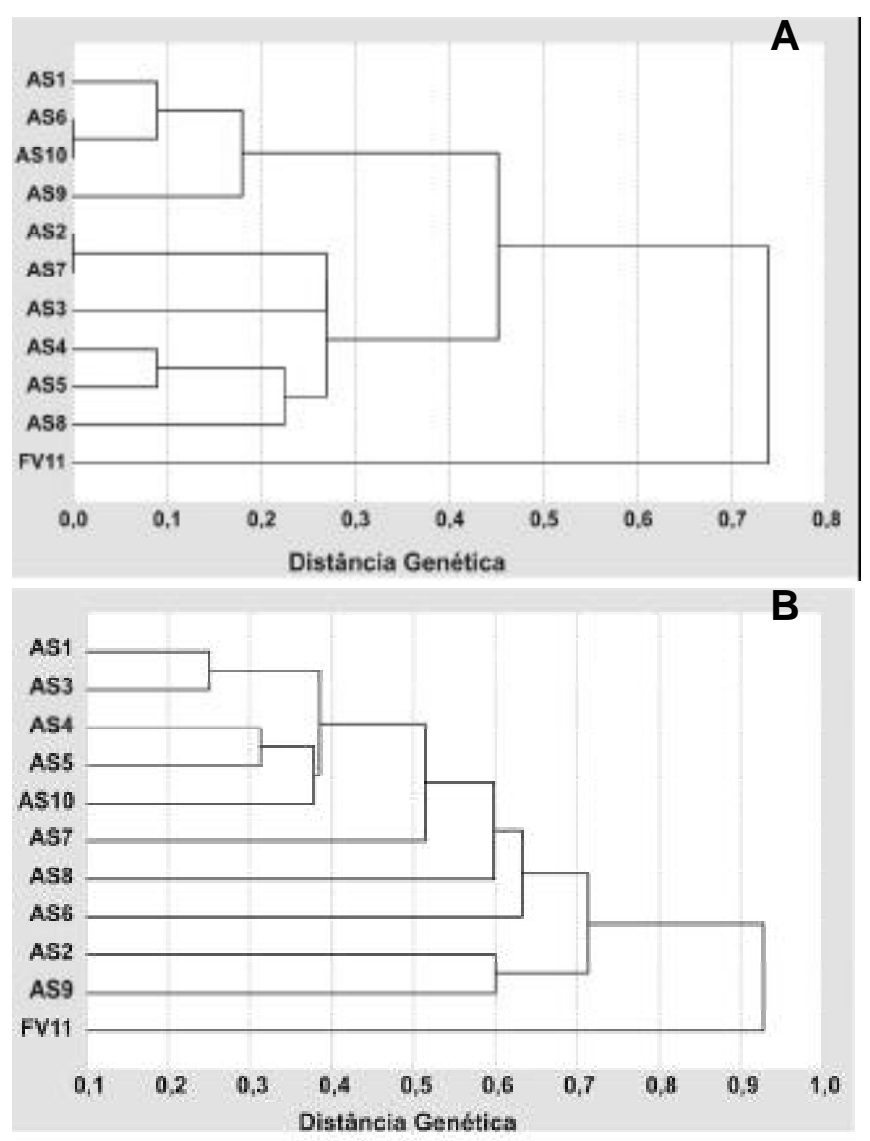

FIG. 2 - Agrupamento de isolados de Acremonium strictum (AS1 a AS10) e de Fusarium verticillioides (FV11), baseado nas distâncias genéticas $(\%)$ entre os indivíduos. Dados obtidos pela análise de variáveis morfofisiológicas (A) e eletroforese de isoenzimas (B).

foram divididos em três grupos, considerando um limite arbitrário de $65 \%$ de distância genética relativa. Grupo 1: AS1, AS3, AS4, AS5, A10, AS7, AS8, AS6; grupo 2: AS2, AS9; e o grupo 3: FV11. Exceto pela composição do Grupo 3 , pode-se observar que, em sua maioria, os resultados da eletroforese de isoenzimas diferiram daqueles obtidos pela análise de aspectos morfofisiológicos. Isto, provavelmente, deve-se ao fato de não haver qualquer relação genotípica entre as variáveis morfológicas consideradas e os sistemas isoenzimáticos analisados. Os sistemas enzimáticos $\mathrm{PO}$ e SOD não apresentaram atividade para os isolados de $A$. strictum e F. verticillioides. Do mesmo modo, Kerssies et al. (1994) e Leuchtmann \& Clay (1990) relataram ausência de atividade de tais sistemas, respectivamente para $F$. oxysporum e Acremonium sp. Entretanto, Vieira (1996) e Skovgaard \& Rosendahl (1998) observaram atividade para estas enzimas em Colletotrichum sp. e F. oxysporum, respectivamente. Os isolados AS1-AS3, AS4-AS5, AS2AS9, AS5-AS6 e AS7-AS8-AS10 apresentaram perfis isoenzimáticos semelhantes para os sistemas ALP e EST, ALD e ALP, ALD e EST, ACP, MDH, respectivamente. No presente experimento, verificou-se que apenas os pares de isolados de A. strictum originários dos estados do Paraná
(AS5-AS6) e de Goiás (AS7-AS8) apresentaram correlação entre o padrão isoenzimático e a origem geográfica dos mesmos.

A análise conjunta dos resultados deste experimento permitiu observar que, na maioria dos casos, isolados provenientes de um mesmo estado (AS1 e AS2, ambos de Minas Gerais; AS3 e AS4, ambos de São Paulo; etc.) apresentaram fenótipos mais variados do que isolados oriundos de estados diferentes (AS1 e AS3; AS5 e AS9; AS4 e AS8). Este fato deveu-se, provavelmente, à utilização de isolados obtidos de genótipos hospedeiros com base genética diferente, exercendo alguma influência sobre o comportamento dos próprios isolados, mais que a origem geográfica dos mesmos. Da mesma forma, Alzate-Marin et al. (1997) não observaram correlação entre os grupos de similaridade genética observados e a origem geográfica dos isolados testados. Exceções à parte, e observando-se os resultados da aplicação das duas técnicas, constatou-se que o agrupamento de isolados afins de $A$. strictum não permitiu estabelecer um padrão. Estes resultados apresentam fundamento se considerarmos que dificilmente a expressão dos aspectos morfofisiológicos e isoenzimáticos dos isolados estariam sendo condicionados pelos mesmos alelos.

\section{REFERÊNCIAS BIBLIOGRÁFICAS}

ALFENAS, A. C. Eletroforese de isoenzimas e proteínas afins. Viçosa. SIF. 1998.

ALZATE-MARIN, A.L., BAÍA, G.S., FALEIRO, F.G., CARVALHO, G.A., PAULA JÚNIOR, T.J. de; MOREIRA, M.A. \& BARROS, E.G. de. Análise da diversidade genética de raças de Colletotrichum lindemuthianum que ocorrem em algumas regiões do Brasil por marcadores RAPD. Fitopatologia Brasileira 22:85-88. 1997.

ANDRADE, D.E.G.T., ASSIS, T.C., MICHEREFF, S.J. \& MENEZES, M. Variabilidade isoenzimática entre isolados de Fusarium oxysporum f.sp. lycopersici de uma área de plantio de tomateiro. Fitopatologia Brasileira 22:243. 1997 (Resumo).

BURGESS, T., MALAJCZUK, N. \& DELL, B. Variation in Pisolithus and basidiospore morphology, culture characteristics and analysis of polypeptides using 1D SDS-PAGE. Mycological Research 99:1-13. 1995.

CAMARGO, T.V., MENEZES, M. \& ASSIS, T.C. Caracterização de isolados de Fusarium moniliforme através da análise eletroforética em gel de poliacrilamida. Fitopatologia Brasileira 22:254. 1997 (Resumo).

CERQUEIRA, A. de O., NEWMAN LUZ, E.D.M. \& ROCHA, C.S.S. Caracterização morfológica e biométrica de alguns isolados de Phytophthora spp. da micoteca do centro de pesquisas do cacau. Fitopatologia Brasileira 24:114-119. 1999.

FUNGARO, M. H. P. PCR na micologia. Biotecnologia: ciência \& desenvolvimento 3:12-16. 2000.

GAMS, W. Cephalosporium-artige Schimmelpilze (Hyphomycetes). Stuttgart. G. Fischer. 1971

GOIS, M.R.B., REIFSCHNEIDER, F.J.B. \& MILLER, R.N.G. Estudo da variabilidade de isolados de Verticillium dahliae. Fitopatologia Brasileira 22:267. 1997 (Resumo). 
HUSS, M.J., CAMPBELL, C.L., JENNINGS, D.B. \& LESLIE, J.F. Isozyme variation among biological species in the Gibberella fujikuroi species complex (Fusarium section Liseola). Applied and Environmental Microbiology 62:3750-3756. 1996.

KERSSIES, A., EVERINK, A., HORNSTRA, L. \& TELGEN, H. J. van. Eletrophoretic detection method for Fusarium oxysporum species in cyclamen and carnation by using isoenzimes. In: Schots, A., Dewey, F.M. \& Oliver, R. (Eds.) Modern assays for plant pathogenic fungi: identification, detection and quantification. Cambridge. CAB International. 1994. pp.57-62.

LEUCHTMANN, A. \& CLAY, K. Isozyme variation in the Acremonium/Epichloë fungal endophyte complex. Phytopathology 85:1133-1139. 1990.

LIMA, J.A.S., MARTINS, L.S.S. \& TAVARES, S.C.C. Caracterização isoenzimática de quinze isolados de Botryodiplodia theobromae Pat. provenientes de diferentes hospedeiros. Fitopatologia Brasileira 22:322. 1997 (Resumo).

LIMONARD, T. A modified blotter test for seed health. Netherlands Journal of Plant Pathology 72:319-321. 1966.

MACHADO, M.C.V., MACHADO, A.L.M. \& MENEZES, M. Patogenicidade e caracterização isoenzimática de isolados de Myrothecium roridum. Fitopatologia Brasileira 22:302. 1997 (Resumo).
MUNSELL, A.H. Munsell book of color: glossy finish collection (2.5R-10G). Maryland. Macbeth Division. 1976.

SKOVGAARD, K. \& ROSENDAHL, S. Comparison of intra and extracellular isozyme banding patterns of Fusarium oxysporum. Mycology Research 102:1077-1084. 1998.

SMITH, D. \& ONIONS, A.H.S. The preservation and maintenance of living fungi. Kew. Commonwealth Mycological Institute. 1994.

URBEN, A.F. \& OLIVEIRA, A.S. Caracterização morfológica em diferentes isolados de Fusarium moniliforme infectando sementes transgênicas de milho procedentes dos Estados Unidos. Fitopatologia Brasileira 24: 339. 1999 (Resumo).

VALIM-LABRES, M.E., PRESTES, A.M., SAND, S. van der \& MATSUMURA, A.T.S. Variação no aspecto cultural, morfologia e virulência em isolados de Bipolaris sorokiniana de trigo. Fitopatologia Brasileira 22:483-487. 1997.

VÉRAS, S.M. de, GASPAROTTO, L. \& MENEZES, M. Avaliação isoenzimática de Colletotrichum guaranicola. Fitopatologia Brasileira 22:323. 1997 (Resumo).

VIEIRA, M.G.G.C. Utilização de marcadores moleculares no monitoramento da qualidade sanitária e nível de deterioração de sementes de algodoeiro. (Tese de Doutorado). Lavras. Universidade Federal de Lavras. 1996. 